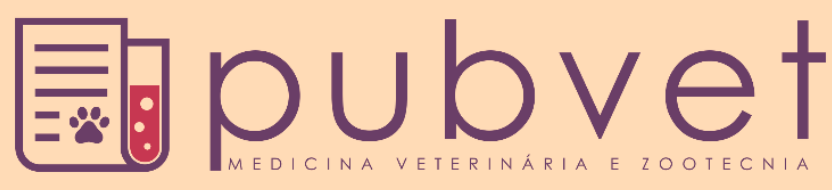

https://doi.org/10.31533/pubvet.v15n08a891.1-4

\title{
A importância da linguagem corporal na consulta veterinária com tutores idosos, desafios e limitações
}

\author{
Anderson Scherer ${ }^{*} \bullet$, Ana Beatriz Maria de Lima ${ }^{2}$, Daniella Nascimento Azevedo ${ }^{2}$, Marta \\ Jaqueline Nascimento Barbosa ${ }^{2}$, Natieli Caroline Barbosa ${ }^{2}$, Nayara Azevedo Schwittay ${ }^{20}$, \\ Nicolas Yago Guiron², Yaksha Jordão Felis ${ }^{2}$
}

'Professor da Universidade Anhembi Morumbi, Comunicação Clínica e Projeto de Integração Saúde e Comunidade, São Paulo - SP Brasil. ${ }^{2}$ Bacharelando em Medicina Veterinária na Universidade Anhembi Morumbi. São Paulo, SP - Brasil.

*Autor para correspondência, E-mail: asscherer@anhembi.br

\begin{abstract}
Resumo. Este trabalho refere-se a importância da linguagem corporal na consulta veterinária com tutores idosos, seus desafios e limitações. Ao longo de tal, portanto, discorre-se sobre este assunto, baseado em um questionário realizado com uma médica veterinária abordando questões diárias em uma rotina clínica com idosos, suas dificuldades e possíveis métodos de melhora para essa condição. No final do artigo, serão discutidos estes resultados, sendo apresentadas sugestões para a investigação futura.
\end{abstract}

Palavras chave: Comunicação não verbal, idosos, linguagem corporal

\section{The importance of body language in veterinary consultation with elderly tutors, challanges and limitations}

\begin{abstract}
This work intends to carry out the importance of body language in veterinary consultation with elderly tutors, it challanges and limitations. Throughout the work we will discuss this subject, based on a questionnaire with a veterinarian, addressing daily issues in a clinical routine with the elderly, their difficulties and possible methods of improvement for this condition. At the end of the article, these results will be discussed and suggestions for future research will be presented.
\end{abstract}

Keywords: Non-verbal communication, elderly, body language

\section{Introdução}

O presente artigo tem como intuito estudar a relação do profissional de medicina veterinária com idosos que levam seus animais para um atendimento em clínica, visando identificar as principais dificuldades existentes na relação e critérios para melhor atendê-los como, por exemplo, a linguagem corporal (comunicação não verbal).

O Brasil está em transição demográfica (Vasconcelos \& Gomes, 2012). A população envelhece e com isso surgem desafios para a humanidade. Todas as áreas devem estar preparadas e planejadas para o envelhecimento populacional (Miranda et al., 2016). Para tal, é importante que os profissionais da saúde se enquadrem nas necessidades comunicacionais com este grupo etário (Peduzzi, 2001).

Tendo em vista que ao envelhecer, o ser humano passa por transformações tais como sociais, comportamentais e cognitivas, espera-se um declínio em relação a sua linguagem e ao seu desempenho físico (Machado \& Brêtas, 2006). O desempenho em questão abrange a dificuldade no canal receptor e transmissor de mensagem, podendo afetar a fala, a interpretação, a leitura e diversas exigências presentes na necessidade de se comunicar em qualquer situação (Garcia \& Mansur, 2006). 
Contudo, o problema de pesquisa que norteia este estudo é dado pela questão "Como um médico veterinário deve se portar frente a uma consulta clínica com idosos?" Para responder à questão, o objetivo geral do artigo é compreender as dificuldades de comunicação dos idosos. Já o objetivo secundário é identificar maneiras que facilitem a comunicação para o melhor atendimento clínico para um idoso. A linguagem corporal (comunicação não verbal), portanto, pode ser uma ótima opção para ser utilizada nesses casos, assim como a comunicação visual.

\section{Material e métodos}

Foi utilizada uma abordagem qualitativa com entrevistas em profundidade e em seguida, foi feita uma análise dos discursos coletados. Para a entrevista, foi elaborado um roteiro, como consta no anexo A, com nove perguntas abertas, respondidas por uma veterinária.

A veterinária entrevistada atende pelo nome de Doutora Cristiane Gatto está com 39 anos e atua na área há 10 anos. Ela trabalha na clínica "Caodilheiras", onde mais especificamente atua na área de clínica geral, de segunda a sábado.

As questões do roteiro pretendiam identificar como a entrevistada se porta quando atende um tutor idoso com diferentes dificuldades, como audiovisual, perda de memória e entre outros. Tais questões tentaram abordar também técnicas e métodos que poderiam ser utilizados neste tipo de consulta.

\section{Resultados e discussão}

\section{Comunicação dos profissionais da área da saúde com os idosos e seus desafios e limitações}

Para agregar qualidade na relação interpessoal com agentes dos serviços da saúde, há diversas competências de comunicação que devem ser adotadas por profissionais da área como, por exemplo, não utilizar linguagem técnica, comunicar as informações necessárias no ritmo do paciente ou do tutor, um tópico por vez, utilizar diagramas, tabelas e desenhos para melhor compreensão (a chamada comunicação visual), verificar se foi compreendido e repassar toda a consulta resumidamente e, se necessário; respeitar os valores, deixar claro que tal pode se questionar a qualquer momento (Lamela \& Bastos, 2012; Nascimento et al., 2005). As relações entre as concepções de idosos e de auxiliares de enfermagem sobre o cuidado em ambiente hospitalar é importante (Nascimento et al., 2005).

Além disso, os profissionais da saúde recebem a função de cuidar. Cuidar para os autores Brum et al. (2005) deve ir além dos cuidados da saúde, deve atender as necessidades físicas e não físicas, levando em consideração todo o contexto que cerca o cliente ou paciente. Portanto, é necessário deixar com que os tutores idosos se sintam à vontade para contarem suas histórias, lembranças e se questionarem, uma vez que muitos deles se sentem desamparados e ignorados. É essencial não se impor e subestima-los deixando-os livres para expressar suas angústias, dúvidas e sentimentos.

Todo esse contexto é complexo quando o paciente ou tutor é um idoso. O profissional da saúde deve proporcionar conforto e bem-estar e estar preparado para se comunicar verbalmente ou gestualmente com os idosos, suprindo as necessidades assistenciais, incluindo as necessidades não-físicas e sim psicológicas (Brum et al., 2005). Tem-se estudado que a maneira amistosa, a cortesia, o encorajamento, a empatia e a construção de uma parceria no atendimento dos profissionais estão relacionadas com a percepção de qualidade dos cuidados para os idosos (Garcia \& Mansur, 2006).

Segundo os autores Lamela \& Bastos (2012), a capacidade do profissional de compreender o estilo de comunicação do idoso e adaptar o seu ao nível de integração comunicacional aumenta a eficácia e satisfação desta comunicação. Ou seja, esta afirmação leva-se a acreditar que os estilos comunicacionais entre o profissional de saúde com idosos é um dos principais preditores do sucesso no atendimento (Garcia \& Mansur, 2006).

A linguagem corporal é, portanto, indispensável em uma consulta rotineira, uma vez que ela traz um ar de atenção e compreensão ao tutor (gestos de afirmação com a cabeça, postura corporal ereta, contato visual e, se necessário, realizando toques, frases simples, curtas, audíveis, lentas, utilização da linguagem entre outros (Tenenbaum, 1993). Além dessa linguagem corporal, é válido ressaltar que a comunicação visual juntamente com a comunicação não verbal pode ser de um cunho muito eficiente, 
uma vez que a partir de tais posturas é possível realizar desenhos, tabelas, diagramas, receituário em papéis maiores (A4), entre outros métodos. Dessa forma facilitando as consultas com tutores idosos e garantindo uma comunicação clínica mais efetiva. É importante estar atento também às questões relacionadas às diferentes classes sociais dos idosos, tendo em vista que esses, quando de maior poder aquisitivo, tendem à uma participação mais ativa na consulta, o que não se repete em relação idosos com menor poder aquisitivo (Lamela \& Bastos, 2012). Nesses casos, portanto, a consulta clinica deve fluir de maneira mais empática do que o costume, garantindo total entendimento e participação do tutor. Ainda, seguindo o pensamento dos autores Lamela \& Bastos (2012), a tabela seguinte apresenta as competências de uma comunicação de profissionais da área da saúde. Estas competências contribuem para a qualidade das relações interpessoais, incluindo a relação com os idosos (Rodrigues \& Bretas, 2003).

Tabela 1. Competências de uma comunicação de profissionais da área da saúde que contribuem para a qualidade das relações interpessoais.

- Capacidade de comunicar informação científica e complexa, utilizando linguagem não-técnica e de fácil compreensão.

- Adaptação da quantidade de informação ao ritmo, necessidades e preferências dos doentes e suas famílias.

- Utilização de diagramas para auxiliar a compreensão da informação.

- Explicação das possibilidades, vantagens e riscos de cada opção terapêutica.

- Respeito e consideração pelos valores e expectativas dos pacientes durante o processo de tomada de decisão quanto à melhor escolha terapêutica.

- Utilização de competências de encorajamento com vista a estimular o envolvimento do doente.

- Criação de um ambiente no qual os doentes se sintam confortáveis e seguros para fazerem perguntas.

- Dar tempo aos doentes para digerir e compreender a informação.

- Avaliação das crenças e veracidade da informação que os doentes apresentam fase à terapêutica.

- Dar direito a contra argumentação do doente quanto à terapêutica selecionada.

- Verificação da compreensão do paciente.

- Utilização de competências de negociação.

A análise dos resultados do questionário feito se mostrou concatenada com o referencial teórico, abordando algo que na prática nem sempre é exercida. A atenção especial com os idosos se faz necessária para o desenvolvimento de uma consulta virtuosa e bem-sucedida. Essa prudência estima acima de tudo o entendimento dos idosos retratando em um efetivo tratamento para o seu animal.

Tendo em vista que o avanço da idade acarreta numa mudança comportamental e cognitiva, é importante se atentar as possíveis dificuldades que o idoso possa apresentar durante uma consulta clínica e, acima de tudo, saber lidar e agir com tal situação.

A médica veterinária em questão demonstrou-se consciente com o detalhamento na consulta com o idoso, lembrando sempre da importância da comunicação não verbal para o melhor entendimento do tutor. Ela refere-se ao uso de tabelas, receitas diferenciadas, esquemas e o uso da expressão facial e gestos de uma forma mais significativa e propositiva.

O trato empático com a situação dos idosos se mostra presente no seu atendimento, levando em conta quesitos emocionais e o lugar de fala do próprio tutor. Em casos mais específicos, tais como deficiência auditiva ou visual, ela faz o uso de linguagem mais clara e pausada, além de aumentar o tom de voz (chamada para linguagem). Ela também ressalta a questão da importância de possuir paciência; porém, sempre impondo limites e motivando/incentivando o tutor. De forma geral, o comportamento da veterinária para com os tutores idosos, se demonstrou apropriado frente ao protocolo.

\section{Considerações finais}

É essencial, portanto, que uma consulta clínica com a presença de tutores idosos, independente da área da saúde em questão, deva ser sucinta e muito bem elaborada, uma vez que a maior parte da população idosa possui restrições quando falamos do entendimento de assuntos mais complexos. Por conseguinte, é de justa causa que seja utilizado macetes, métodos e técnicas para que esses vínculos sejam melhorados e se tornem ótimas relações interpessoais. É possível então declarar que a comunicação não verbal (assim como já dito, a linguagem corporal e visual) são necessárias e positivas se incluídas no dia a dia, em consultas com idosos. Acentua-se que a realidade retratada pela Médica Veterinária Cristiane Gatto neste artigo não é a veracidade vista em grande parte de consultas clínicas rotineiras, uma vez que os idosos ainda são muito destratados em dias atuais, e muitos profissionais não atuam seguindo protocolos de maneira adequada e conveniente. Lembrar que a comunicação afetiva, 
todavia pode ser também um ótimo método de acolhimento para os idosos em consulta, já que muitas vezes eles se sentem sozinhos e carente.

\section{Referências}

Brum, A. K. R., Tocantins, F. R., \& Silva, T. J. E. S. (2005). O enfermeiro como instrumento de ação no cuidar do idoso. Revista Latino-Americana de Enfermagem, 13(6), 1019-1026.

Garcia, F. H. A., \& Mansur, L. L. (2006). Habilidades funcionais de comunicação: idoso saudável. Acta Fisiátrica, 13(2), 87-89.

Lamela, D., \& Bastos, A. (2012). Comunicação entre os profissionais de saúde e o idoso: uma revisão da investigação. Psicologia \& Sociedade, 24(3), 684-690.

Machado, A. C. A., \& Brêtas, A. C. P. (2006). Comunicação não-verbal de idosos frente ao processo de dor. Revista Brasileira de Enfermagem, 59(2), 129-133.

Miranda, G. M. D., Mendes, A. da C. G., \& Silva, A. L. A. (2016). O envelhecimento populacional brasileiro: desafios e consequências sociais atuais e futuras. Revista Brasileira de Geriatria e Gerontologia, 19(3), 507-519.

Nascimento, M. A. L., Figueiredo, N. M. A., Cardim, M. G., \& Ghidini, R. (2005). A comunicação visual transmitida pela imagem corporal da enfermeira aos acadêmicos de enfermagem. Online Brazilian Journal of Nursing, 4(1), 26-31.

Peduzzi, M. (2001). Equipe multiprofissional de saúde: conceito e tipologia. Revista de Saúde Pública, 35(1), 103-109.

Rodrigues, M. R., \& Bretas, A. C. P. (2003). As relações entre as concepções de idosos e de auxiliares de enfermagem sobre o cuidado em ambiente hospitalar. Acta Paul Enfermagem, 16(4), 38-48.

Tenenbaum, D. (1993). A linguagem corporal. In Rio de Janeiro (pp. 1-8).

Vasconcelos, A. M. N., \& Gomes, M. M. F. (2012). Transição demográfica: a experiência brasileira. Epidemiologia e Serviços de Saúde, 21(4), 539-548.

Histórico do artigo:

Recebido: 24 de março de 2021

Aprovado: 1 de maio de 2021 Licenciamento: Este artigo é publicado na modalidade Acesso Aberto sob a licença Creative Commons
Atribuição 4.0 (CC-BY 4.0), a qual permite uso irrestrito, distribuição, reprodução em qualquer meio,
desde que o autor e a fonte sejam devidamente creditados. 